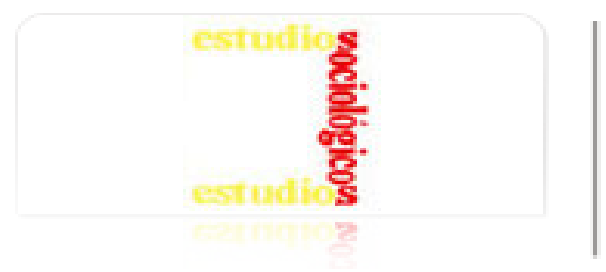

Estudios Sociológicos

ISSN: 0185-4186

revistaces@colmex.mx

El Colegio de México, A.C.

México

Solís, Patricio

Cambio estructural y movilidad ocupacional en Monterrey, México

Estudios Sociológicos, vol. XXIII, núm. 67, enero-abril, 2005, pp. 43-74

El Colegio de México, A.C.

Distrito Federal, México

Disponible en: http://www.redalyc.org/articulo.oa?id=59811838002

- Cómo citar el artículo

- Número completo

- Más información del artículo

Página de la revista en redalyc.org

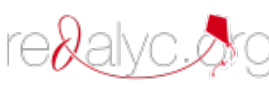

Sistema de Información Científica

Red de Revistas Científicas de América Latina, el Caribe, España y Portugal Proyecto académico sin fines de lucro, desarrollado bajo la iniciativa de acceso abierto 


\title{
Cambio estructural y movilidad ocupacional en Monterrey, México*
}

\author{
Patricio Solís
}

\section{Introducción}

LA SEGUNDA MITAD DEL SIGLO XX FUE EL ESCENARIO de profundos cambios económicos, sociales y demográficos en México. En las cuatro décadas que transcurrieron entre 1940 y 1980, el país experimentó un acelerado proceso de industrialización y urbanización. Luego, durante los años ochenta, el agotamiento del modelo de desarrollo basado en la sustitución de importaciones derivó en una profunda crisis económica, que produjo un incremento marcado de la pobreza y redujo los niveles de bienestar de la población. Más tarde, a finales de los ochenta, las medidas de liberalización económica se acompañaron de cierta reactivación del crecimiento económico, aunque éste tuvo un ritmo bastante menor al observado antes de la década perdida de los ochenta.

La investigación social y sociodemográfica reciente en México se ha preocupado principalmente por el estudio de los efectos de estas transformaciones en la distribución del ingreso y los niveles de pobreza (Boltvinik, 2001; Cortés, 1998), así como en el análisis de las respuestas de los hogares pobres urbanos a las presiones económicas en los periodos de crisis, a través de las estrategias de sobrevivencia (González de la Rocha, 1994; Selby, Murphy y Lorenzen, 1990; Tuirán 1993). No obstante, poco se sabe acerca de los efectos de estos cambios en la estratificación y la movilidad social, de tal

* Este trabajo reúne parte de los resultados de mi tesis doctoral, presentada en la Universidad de Texas en Austin. Agradezco el apoyo financiero otorgado para este estudio por el Conacyt, la Universidad de Texas en Austin, el Population Council, y la Fundación Andrew W. Mellon. También agradezco los comentarios y sugerencias a versiones previas de este trabajo de Bryan R. Roberts, Joseph E. Potter, Harley L. Browning y Fernando Cortés, así como de dos lectores anónimos. 
forma que hoy en día es difícil responder con certeza a preguntas como las siguientes: ¿Cuáles son los patrones emergentes de estratificación social en México? ¿Existe o no una reducción en la movilidad social ascendente en comparación con el periodo de alto crecimiento económico previo a la década de los ochenta? ¿Cuál es en la actualidad la correlación entre las distintas dimensiones de la estratificación, como el trabajo, los ingresos y la escolaridad? ¿Hasta qué punto las oportunidades de movilidad se distribuyen en forma equitativa o desigual entre los individuos provenientes de distintos estratos sociales?

La escasez de aportes sustantivos recientes llama la atención porque no hace mucho tiempo estos temas ocuparon un lugar central en la agenda de investigación sociológica en México y en otros países de América Latina (Filgueira, 2000). Estudios como los de Balán, Browning, y Jelin (1977), en Monterrey, y de Muñoz, Oliveira y Stern (1977), en la ciudad de México, documentaron la forma en que el proceso de industrialización, aunado a la intensa migración rural-urbana, dio lugar a un régimen de alta movilidad social, donde las desigualdades de clase eran de cierta manera atenuadas por las elevadas tasas de movilidad social ascendente. ${ }^{1}$

Se tiene poca evidencia empírica acerca de los cambios en la movilidad social en años recientes. En este artículo analizo estos cambios, con énfasis en la movilidad ocupacional para el caso específico de Monterrey, una ciudad que ilustra las características del desarrollo industrial basado en la sustitución de importaciones, los efectos disruptivos de la crisis de los ochenta, y las formas emergentes de acumulación económica que han acompañado a la liberalización y la globalización. Monterrey es también un caso ideal para un análisis de esta naturaleza porque ofrece la rara oportunidad de contrastar empíricamente los patrones de movilidad ocupacional en dos periodos de su historia reciente: el primero transcurre entre la década de los cuarenta y los sesenta, y corresponde al auge económico asociado a la sustitución de importaciones; mientras que el segundo se extiende a las dos últimas décadas del siglo, cuando la economía local enfrentó los estragos del quiebre en el modelo económico y se adaptó con relativo éxito a las nuevas condiciones económicas.

En el artículo presento lo que considero son las tres principales tendencias en la movilidad ocupacional en Monterrey. La primera es la continuidad

${ }^{1}$ Este régimen de intensa movilidad ocupacional ascendente no era exclusivo de México, sino que se presentaba en todos los países de América Latina que experimentaron una rápida industrialización basada en la sustitución de importaciones. El estudio pionero sobre la relación entre industrialización y movilidad es el de Germani (1963) sobre la movilidad social en Argentina. 
en las tasas de movilidad estructural ascendente registrada hasta antes de los ochenta, aunque ahora asociada a la expansión de las ocupaciones no manuales. En segundo lugar, se observa en años recientes una disrupción en la correlación entre ocupaciones e ingresos laborales, caracterizada por la caída de los ingresos en las ocupaciones de rango intermedio, lo cual sugiere que la movilidad estructural ascendente en ocupaciones no necesariamente se ha traducido en movilidad ascendente en ingresos. Por último, también se aprecia una creciente inequidad social en el acceso a las oportunidades laborales, que se manifiesta en la mayor importancia de factores ligados a los orígenes sociales - tales como el estrato social de origen - en el logro ocupacional individual.

Antes de discutir estas tendencias, es necesario presentar algunos antecedentes que sirven de contexto a este estudio. En primer lugar, realizo un breve recuento de las transformaciones en la estructura productiva de Monterrey y sus efectos en la creación de oportunidades ocupacionales durante la segunda mitad del siglo pasado. Luego reviso en detalle las herramientas teórico-conceptuales que utilizaré para el análisis empírico de la movilidad ocupacional. Después presento las fuentes de datos para el estudio, así como la estrategia metodológica que lo sustenta. Una vez cubiertos estos antecedentes, procedo a presentar la evidencia que respalda cada una de las tendencias recién apuntadas.

\section{Cambios en la estructura productiva y mercado de trabajo en Monterrey: 1940-2000}

Los cambios en la estructura productiva suelen tener importantes efectos en la movilidad ocupacional, debido a que inciden directamente en la creación y desaparición de oportunidades en el mercado de trabajo. En el Monterrey de la segunda mitad del siglo xx, estos cambios pueden ser trazados en el tiempo a partir de la delimitación de dos amplios periodos. El primer periodo corresponde al crecimiento económico basado en la sustitución de importaciones, y se extiende desde inicios de los cuarenta hasta finales de los setenta. El segundo periodo abarca las últimas dos décadas del siglo y se caracteriza, en principio, por la crisis del modelo de desarrollo basado en la sustitución de importaciones y, posteriormente, por la implantación de un nuevo modelo económico basado en la apertura a los mercados internacionales y el fin del papel rector del Estado en la economía. Durante esta transición, la economía regiomontana experimentó agudas transformaciones que, a su vez, produjeron cambios significativos en el mercado de trabajo. 
Con el fin de identificar estos cambios, conviene partir de una revisión de las características del desarrollo económico de Monterrey durante el periodo de sustitución de importaciones. Desde finales del siglo pasado, el desarrollo económico de Monterrey estuvo estrechamente ligado a la expansión de las actividades manufactureras, pero este crecimiento fue particularmente alto entre 1940 y 1970, justo la etapa de mayor auge de la sustitución de importaciones. ${ }^{2}$ En este periodo, el crecimiento económico de Monterrey tuvo dos rasgos característicos: la concentración en un número limitado de compañías y ramas industriales, y el escaso desarrollo del sector terciario. Las ramas más dinámicas fueron los bienes intermedios, los bienes de capital y los bienes de consumo duradero. La producción de otros minerales no metálicos como el vidrio y el cemento también ocupaba un lugar importante. Además de estas industrias, con raíces en la expansión industrial originaria de la ciudad, se abrieron nuevas ramas de producción; entre ellas, la industria automotriz y la producción de papel y sus derivados.

Los primeros signos de crisis del modelo de sustitución de importaciones se sintieron en Monterrey a principios de la década de los setenta. ${ }^{3}$ No obstante, durante la segunda mitad de la década, la ciudad creció nuevamente a tasas superiores al 6\% anual, debido a que los grandes consorcios locales realizaron cuantiosas inversiones en el contexto del auge petrolero. En este sentido, los años setenta pueden ser considerados como una década más de crecimiento económico acelerado en Monterrey, aunque esta expansión se haya logrado a partir de financiamientos riesgosos (como los créditos en dólares otorgados por acreedores extranjeros), que fueron el antecedente para la crisis de los ochenta.

En este sentido, la crisis económica a principios de los ochenta significó la interrupción de varias décadas de crecimiento industrial sostenido en la ciudad. Luego del estallido de la crisis, los grandes consorcios industriales regiomontanos se encontraron en una situación bastante comprometedora, debido a su insolvencia financiera y la contracción de las ventas en el mercado interno (Pozos Ponce, 1996). Esto los llevó a reducir significativamente

${ }^{2}$ Entre 1940 y 1970, las tasas promedio de crecimiento anual del PIB y del PIB industrial en el país fueron de 6.6 y $8.2 \%$, respectivamente. En 1940, 15\% del PIB se generaba en actividades industriales; para 1970 esta proporción se incrementó a 23\% (Dussel Peters, 1997:122-123). Durante este periodo, el crecimiento económico de Monterrey fue incluso superior al nacional: en 1940 , Monterrey generaba $7.2 \%$ del PIB nacional; para 1950 producía $7.8 \%$ y para 1960 casi el 10\% (Cerutti, 2000).

${ }^{3}$ Después de varias décadas de crecimiento continuo, la producción manufacturera se contrajo en 1971, luego se incrementó nuevamente en forma significativa entre 1972 y 1974 , fue prácticamente nula en 1975 y decreció nuevamente 1976 (Cerutti, 2000). 
sus niveles de operación, lo que a su vez propició una masiva reducción en sus plantas laborales. Entre 1980 y 1982, ALFA, VISA y VITRO, tres de los consorcios industriales privados más importantes de América Latina, con sede en Monterrey, despidieron cerca de 38 mil trabajadores (Pozas, 1993), muchos de los cuales trabajaban en plantas y oficinas establecidas en la ciudad. A éstos habría que sumar los más de 7 mil trabajadores que perdieron su empleo luego del cierre de Fundidora Monterrey a mediados de 1986.

Una vez superados los efectos más adversos de la crisis de los ochenta, la industria regiomontana renovó su crecimiento, aunque en condiciones bastante diferentes a las vigentes durante el periodo de sustitución de importaciones. En el contexto del ingreso de México al GATT en 1986 y la instrumentación de políticas neoliberales a partir del gobierno de Carlos Salinas de Gortari, las grandes empresas regiomontanas desarrollaron estrategias de adaptación y expansión basadas en una mayor integración con los mercados externos (Alba, 1998; Cerutti, 2000; Pozas, 2002). ${ }^{4}$ Si bien estas estrategias permitieron reactivar el crecimiento económico en la ciudad a partir de finales de los ochenta y durante casi toda la década de los noventa (con excepción de la crisis financiera de 1994-1995), el ritmo de crecimiento del sector industrial no alcanzó los niveles observados durante el periodo de sustitución de importaciones. Al mismo tiempo, se presentó una diversificación de las actividades económicas que favoreció la expansión de los servicios.

Este cambio estructural se reflejó en profundas transformaciones en el mercado de trabajo, de las cuales destaco tres por su importancia para el estudio de la movilidad ocupacional. En primer lugar, se presentó un cambio en la estructura sectorial del empleo, que pasó de un claro predominio de las actividades manufactureras a una mayor importancia del sector servicios. El Cuadro 1 muestra la distribución de la PEA por grandes ramas de actividad entre 1966 y 2000. En 1966, justo durante el periodo de mayor auge de la sustitución de importaciones, el empleo en Monterrey estaba claramente dominado por las actividades manufactureras, con $40.9 \%$ de los trabajadores, mientras que las actividades de servicios apenas agrupaban al 25.1\%. Hacia 1978, esta situación no había cambiado sustancialmente, aunque ya se observaba cierta expansión del sector servicios. En cambio, en los nueve años que transcurrieron entre 1978 y 1987, se presentó una acelerada desindustrialización y terciarización de la fuerza de trabajo. La proporción de trabajadores en la industria se redujo de 36.5 a $27.3 \%$, mientras que el porcentaje de tra-

${ }^{4}$ Un ejemplo ilustrativo es Cementos Mexicanos (Cemex), que desarrolló una estrategia de expansión internacional basada en la adquisición de compañías cementeras en distintas regiones del mundo, incluidos Estados Unidos y Europa, lo que la ha llevado a convertirse en la segunda compañía cementera más importante del mundo. 


\section{Cuadro 1}

Distribución de la PEA ocupada de Monterrey por rama de actividad, 1966-2000

\begin{tabular}{lrrrrrrrr}
\hline & 1966 & 1978 & 1983 & 1987 & 1991 & 1994 & 1998 & 2000 \\
\hline Industria & 40.9 & 36.5 & 31.1 & 27.3 & 28.1 & 24.5 & 25.1 & 29.9 \\
Construcción* & 7.7 & 8.5 & 9.5 & 8.8 & 7.3 & 9.4 & 9.8 & 9.2 \\
Comercio & 17.3 & 16.1 & 16.0 & 18.8 & 21.6 & 22.5 & 21.8 & 18.7 \\
Transporte & 6.8 & 4.7 & 5.0 & 4.6 & 5.2 & 5.4 & 5. & 7.2 \\
Servicios & 25.1 & 31.7 & 36.6 & 39.0 & 37.0 & 37.8 & 37.1 & 34.9 \\
Otros** & 2.2 & 2.5 & 1.8 & 1.6 & 0.8 & 0.4 & 0.5 & 0.1 \\
Total & 100.0 & 100.0 & 100.0 & 100.1 & 100.0 & 100.0 & 100.0 & 100.0 \\
\hline
\end{tabular}

* Incluye el empleo en servicios públicos.

** Incluye industria extractiva y agricultura.

Fuentes: 1966: Balán (1968:49); 1978, 1983: Pozos Ponce (1996); 1987-2000: Encuesta Nacional de Empleo Urbano del INEGI (ENEU).

bajadores en los servicios pasó de 31.7 a 39.0\%. A pesar de que el crecimiento industrial se reanudó desde finales de los ochenta, esto no se tradujo inmediatamente en un incremento del empleo manufacturero. De hecho, la proporción de trabajadores en la industria decreció en términos relativos entre 1987 y 1998 (de 27.3 a 25.1\%), y sólo se incrementó a finales de los noventa, hasta alcanzar el $29.9 \%$ de la PEA. A pesar de esta recuperación, resulta claro que hacia el final del siglo el mercado de trabajo regiomontano mostraba una mayor diversificación hacia los servicios y el comercio, en contraste con la situación predominante durante el auge de la sustitución de importaciones. ${ }^{5}$

El segundo cambio es la transformación de la estructura ocupacional (Cuadro 2). En 1965, durante el periodo de auge industrial, la población trabajadora masculina se concentraba en actividades manuales: más de la mitad de los trabajadores varones tenía ocupaciones manuales, $31.9 \%$ ocupaban posiciones manuales de alta calificación ${ }^{6}$ y $22.9 \%$ posiciones manuales de baja calificación. En contraste, las ocupaciones profesionales y gerenciales eran escasas, así como los empleos no manuales de baja calificación: los

${ }^{5}$ Si bien una parte del crecimiento de los servicios y el comercio se debió a la expansión del sector informal, también se presentó un incremento en las actividades terciarias de mayor productividad, como los servicios al productor, así como de los servicios sociales.

${ }^{6}$ La clasificación de ocupaciones utilizada en este cuadro y en secciones subsiguientes se describe en la sección metodológica y en el Cuadro 3. 


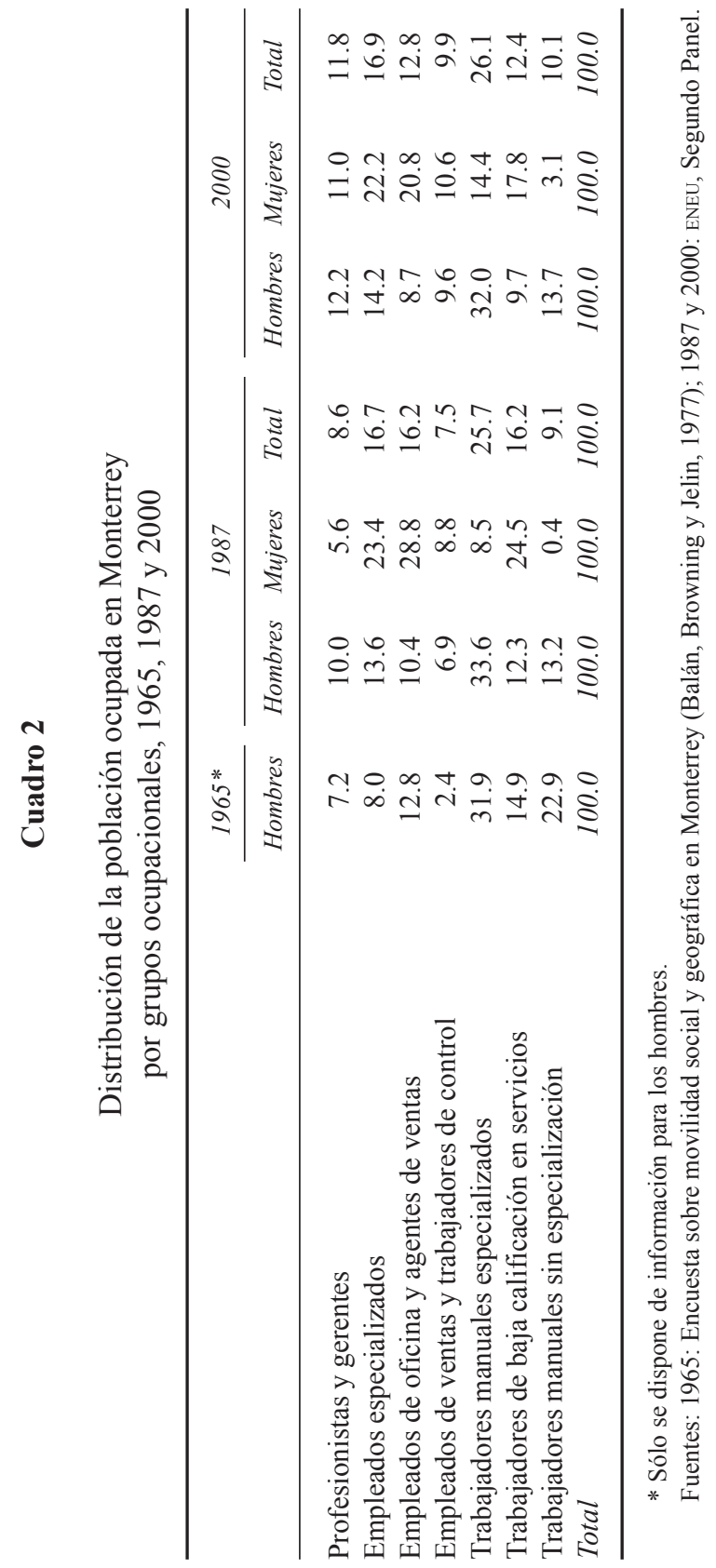


profesionistas y gerentes representaban el 7.2\%; los empleados especializados $8.0 \%$, y los empleados de oficina y agentes de ventas sólo 12.8 por ciento. ${ }^{7}$

La ausencia de información comparable para finales de los setenta no nos permite trazar los cambios en la estructura ocupacional durante el último trecho de la sustitución de importaciones, aunque la evolución sectorial presentada en el Cuadro 1 sugeriría cierta tendencia hacia el incremento en las ocupaciones no manuales, vinculado a la expansión de los servicios. El siguiente corte disponible corresponde a 1987, año en que la economía de la ciudad se encontraba sumergida en una crisis que se prolongaba ya por cinco años. Llama la atención que, a pesar de varios años de recesión, se haya presentado un "ajuste hacia arriba" en la estructura de ocupaciones con relación a 1965: la proporción de profesionistas y gerentes se incrementó de 7.2 a $10.0 \%$ y el porcentaje de empleados especializados, empleados de oficinas y agentes de ventas aumentó de 20.8 a $24.0 \%$. En contraste, dentro de las ocupaciones manuales, se observa un decremento en las posiciones de menor jerarquía (trabajadores de baja calificación en servicios y manuales sin especialización), que pasaron de 37.8 a $25.5 \%$. Estos resultados sugieren que, a pesar de los efectos negativos de la crisis, en el largo plazo prevaleció una tendencia de expansión relativa en las actividades no manuales y contracción de las ocupaciones manuales.

La estructura ocupacional de Monterrey continuó su "ajuste hacia arriba" durante los noventa. ${ }^{8}$ Éste se manifestó en la reducción de la proporción de trabajadores de baja calificación en los servicios, que decreció de $16.2 \%$ en 1987 a $12.4 \%$ en 2000 , así como en el incremento de profesionistas y gerentes (de 8.6 a $11.8 \%$ ) y el aumento en la proporción de empleados en ventas y trabajadores de control (de 7.5 a 9.9\%). Es interesante que la proporción de trabajadores de oficina y agentes de ventas haya decrecido durante este periodo. Tal vez esto se deba a la reducción drástica del empleo en el sector público. En resumen, el contraste entre las distribuciones ocupacionales de 1987 y 2000 refleja una expansión de las posiciones no manuales. Esto sugiere que la tendencia hacia la creación de posiciones no manuales continuó en la última década del siglo xx, aunque en forma menos acentuada que entre 1965 y 1987.

La tercera tendencia es la drástica reducción en las remuneraciones al empleo, que se produjo por los efectos acumulados de las crisis de 1982, 1987 y 1994-1995, así como de las políticas de contención salarial instrumentadas

${ }^{7}$ No se cuenta con información para las mujeres ocupadas. No obstante, en 1965 la tasa de participación laboral femenina era muy baja, por lo que la estructura ocupacional masculina refleja en buena medida la situación del mercado laboral en su totalidad.

${ }^{8}$ Debido a que ya se cuenta con información para ambos sexos, la comparación entre 1987 y 2000 se realiza con base en el total de la PEA ocupada. 
mediante los "pactos económicos" de los ochenta (Lustig, 1998). Es verdad que, hacia el final del siglo, los ingresos ocupacionales medios eran mayores en Monterrey que en otras ciudades del país (Solís, 2002). No obstante, la evolución de los salarios medios en el tiempo fue similar en Monterrey que en el conjunto nacional: entre 1979 y 1987 tuvieron reducciones significativas; sufren cierta recuperación entre 1988 y 1993; experimentan una nueva caída entre 1994 y 1995, y finalmente recuperan algo del terreno perdido durante la segunda mitad de los noventa (Dussel Peters, 1997 y 2003). Como resultado de estas fluctuaciones, los ingresos laborales en la ciudad mostraron un decremento en términos reales con respecto a su nivel a finales de los setenta.

En síntesis, el cambio estructural experimentado por la economía regiomontana en las dos últimas décadas del siglo tuvo profundas implicaciones en el mercado de trabajo, entre las que destacan la terciarización del empleo, la expansión de ocupaciones no manuales y el deterioro de los ingresos laborales. Son estas transformaciones las que proporcionan el contexto para el análisis de la movilidad ocupacional que se presenta en este artículo.

\section{Antecedentes conceptuales y metodológicos para el estudio de la movilidad ocupacional}

Antes de proceder con la presentación de los resultados empíricos es necesario discutir brevemente ciertos aspectos conceptuales y metodológicos relacionados con el estudio de la movilidad ocupacional. Esta área de investigación se inscribe en el conjunto más amplio de estudios sobre estratificación y movilidad social, que es uno de los campos con mayor desarrollo teórico y conceptual en la sociología. Las aproximaciones teóricas y las herramientas metodológicas asociadas al estudio de la movilidad social son tanto diversas como complejas, por lo que se deben clarificar conceptos y métodos antes del análisis empírico. Este ejercicio de clarificación debe incluir al menos los siguientes tres aspectos: a) las dimensiones de la estratificación social que se estudiarán; b) los tipos de movilidad social que se pretenden analizar, y c) si el interés es sólo delinear los rasgos estructurales de la movilidad a escala agregada, o también analizar los factores que inciden sobre la movilidad individual.

\section{Las dimensiones de la estratificación social}

En un sentido amplio, los sistemas de estratificación social pueden definirse como el conjunto de instituciones y sistemas de relaciones sociales que regu- 
lan la forma en que los activos sociales son distribuidos entre sus miembros (Kerbo, 1996). Una de las primeras preguntas que surgen al plantear esta definición es determinar cuáles son esos activos. Se reconoce que estos activos pueden ser de muy diversa índole. Así, por ejemplo, Grusky (1994:4) propone una clasificación de siete tipos de activos: económicos, políticos, culturales, sociales, honoríficos, civiles y humanos.

Cada uno de estos tipos de activos podría considerarse como una dimensión independiente de la estratificación social. No obstante, la investigación sobre movilidad social adopta por lo general una estrategia "reduccionista", consistente en sintetizar esta multidimensionalidad a través de la agrupación de los individuos en un número limitado de categorías, estratos o clases (Grusky, 1994). ${ }^{9}$ Se han privilegiado las clasificaciones jerárquicas de ocupaciones como criterio de agrupación, pues se sostiene que en las sociedades modernas el mercado de trabajo es, aunque no el único, el medio fundamental para la distribución de activos de diversa índole. ${ }^{10}$ En este artículo, adopto esta perspectiva, por lo que analizaré sólo la movilidad ocupacional. No obstante, al estudiar los cambios en el tiempo en la movilidad ocupacional es necesario retomar el problema de la multidimensionalidad en la estratificación, pues es posible que las retribuciones de distinta índole asociadas a cada ocupación hayan cambiado en el tiempo, lo que le daría un significado distinto a la movilidad ocupacional. Como señalé arriba, en el caso de México, una de las dimensiones más susceptibles a estos cambios ha sido los ingresos laborales. Es por ello que pongo especial atención a los cambios en el tiempo en los ingresos por trabajo.

\section{Los tipos de movilidad social}

Otro aspecto que debe clarificarse es qué tipo de movilidad ocupacional se pretende analizar. Existen distintas formas de conceptualizar y cuantificar la movilidad ocupacional, cada una con supuestos teóricos y metodológicos distintos, por lo que si se comparan distintos tipos de movilidad se puede lle-

${ }^{9}$ Detrás de esta estrategia existen al menos dos supuestos básicos: que existe una alta correlación en la distribución de activos entre las distintas dimensiones de la estratificación y que el criterio de agrupación adoptado refleja en forma aceptable la desigualdad en estas distribuciones altamente correlacionadas.

${ }^{10}$ No obstante, debe aclararse que los estudios de movilidad social no se han limitado al análisis de la movilidad ocupacional. De hecho, en la literatura sobre movilidad social abundan ejemplos donde se adoptan otros criterios de clasificación, como son la escolaridad y los ingresos. 
gar a conclusiones empíricas muy diversas e incluso antagónicas. En este sentido, es importante precisar al menos tres aspectos de la movilidad: su $d i$ rección, esto es, si es horizontal o vertical; su carácter generacional, o sea si es intrageneracional o intergeneracional, y su origen, que puede ser estructural o de circulación (Kerbo, 1996).

La movilidad horizontal puede definirse como el movimiento entre posiciones con el mismo rango en la estructura social. En cambio, la movilidad vertical consiste en el movimiento entre posiciones de distinta jerarquía. Si bien ambas formas de movilidad son de interés sociológico, la movilidad vertical ha sido objeto de mayor atención en los estudios de estratificación social, pues revela el grado de fluidez al interior de la estructura de clases o estratos sociales, de tal forma que, ceteris paribus, una mayor movilidad vertical significa que existe más igualdad de oportunidades y, presumiblemente, un menor grado de estructuración al interior de las clases sociales (Giddens, 1989; Kingston, 2000). En este artículo, me concentro en el análisis de la movilidad vertical.

La movilidad intrageneracional es aquella que experimentan los individuos a lo largo de su curso de vida. En contraste, la movilidad intergeneracional es aquella que se presenta entre las posiciones de los padres y los hijos. El análisis que sigue se realizará exclusivamente con la movilidad intergeneracional. Esto se debe, por un lado, a que los cambios de largo plazo en la movilidad ocupacional se observan en forma más nítida a través de la movilidad intergeneracional, pues ésta abarca periodos más largos de tiempo y, por el otro, a que al contrastar las ocupaciones de padres e hijos es posible tratar uno de los temas centrales en el estudio de la movilidad social, que es el grado en que los orígenes sociales inciden sobre el destino de los individuos.

Por último, la movilidad estructural es aquella que se genera directamente a partir de los cambios globales en la estructura de posiciones (por ejemplo, la mayor creación de empleos en la cima de la estructura ocupacional que en la base). En cambio, la movilidad de circulación es aquella que tiene lugar tanto en un sentido descendente como ascendente y no es el resultado de los cambios "forzados" que impone la transformación de la estructura de posiciones. Los niveles de movilidad estructural indican hasta qué punto los cambios estructurales en una sociedad, tales como la transformación de una economía agrícola a otra industrial, la expansión de los servicios en las sociedades post-industriales, o el incremento generalizado de los niveles de escolaridad, crean o destruyen las oportunidades colectivas para la movilidad social, independientemente del origen social de los individuos (Hout, 2003). Como describí antes, Monterrey experimentó transformaciones de esta índole en su mercado de trabajo durante las últimas décadas, y en este 
artículo reviso cómo estas transformaciones incidieron en la movilidad estructural.

\section{Las estructuras de movilidad y el proceso de logro ocupacional}

Por último, otro punto que es importante clarificar es si se busca estudiar únicamente los rasgos estructurales de la movilidad ocupacional (esto es, el análisis de las propiedades de la tabla de movilidad social), o bien, si se pretende analizar los determinantes de la movilidad individual. El análisis de las tablas de movilidad social a partir de técnicas como los modelos de regresión loglineal ha dado origen a una serie de estudios que permiten comparar el grado de movilidad en distintas sociedades. ${ }^{11}$ No obstante, la mayoría de estos estudios ha dejado de lado el análisis de los factores que inciden en el logro ocupacional a escala individual. Blau y Duncan (1967) fueron los pioneros en el estudio formal de estos factores, al analizar las formas en que los orígenes sociales contribuyen al logro ocupacional a través de la mediación de variables como la escolaridad, las aspiraciones y el ambiente familiar. A partir de entonces, los estudios sobre los determinantes del logro individual se han convertido por sí mismos en una subdisciplina en el área de la estratificación social (véase por ejemplo, los trabajos de Sewell, Haller y Portes (1969), Hauser y Featherman (1977), Hauser, Tsai y Sewell (1983) y Grusky y DiPrete (1990)).

Como señalé antes, en este artículo analizo los cambios en la movilidad estructural en Monterrey, pero también exploro algunos determinantes del logro ocupacional a escala individual. Esto permite introducir a la discusión el tema de la desigualdad de oportunidades, que es uno de los tópicos emergentes en la agenda de la investigación social en América Latina. Todas las sociedades conocidas son desiguales en la distribución de los recursos y, además, poseen mecanismos institucionales que rigen la repartición de los mismos. Estos mecanismos pueden ser de distinta índole, pero en general se agrupan en dos categorías: los asociados a los orígenes sociales y los asociados al mérito individual. Los mecanismos asociados a los orígenes sociales son aquellos que se basan en características que los individuos heredan o poseen al nacimiento, como son el estrato social de origen, la raza o el género. Los mecanismos asociados al mérito son aquellos que dependen de características que son adquiridas a través del esfuerzo individual, como podría

\footnotetext{
${ }^{11}$ El estudio clásico en esta corriente es el de Erikson y Goldthorpe (1992), en el que se comparan las tendencias en la movilidad social en doce países industrializados.
} 
ser el nivel de instrucción en un marco de equidad en el acceso a las oportunidades educativas.

Uno de los principales postulados de la teoría liberal del industrialismo (Erikson y Goldthorpe, 1992) es que en la medida en que avanza el proceso de industrialización, se logra una mayor equidad en las oportunidades de movilidad social, de tal forma que los individuos con orígenes sociales diferentes compiten en términos de creciente igualdad para alcanzar (o evitar) ciertas posiciones sociales. En la práctica, este postulado implica que, junto con la industrialización, se reduce la importancia de variables asociadas a los orígenes sociales (particularmente el estrato social de origen) como determinantes de la movilidad social, al tiempo que adquieren mayor relevancia los factores asociados al mérito individual. Esta predicción, que está presente explícitamente en el trabajo de varios autores — por ejemplo, Treiman (1970)y en forma implícita en el enfoque funcionalista de Parsons, es aún objeto de un amplio debate, pues diversos autores sostienen que las tendencias en la movilidad social —y más específicamente en la equidad de oportunidadesdependen no sólo de la evolución de la estructura económica, sino también de los arreglos institucionales que se adoptan en cada sociedad para mitigar (o exacerbar) el efecto de los orígenes sociales sobre el logro individual. Esta última posición es respaldada principalmente por una corriente de sociólogos europeos que ha enfatizado el papel del Estado de Bienestar como institución reguladora de los regímenes de estratificación social en aquel continente (Erikson y Goldthorpe, 1992; Esping-Andersen, 1993; Mayer, 1991 y 1997), así como algunos autores norteamericanos —en particular, DiPrete et al., (1997 y 2001) - que han enfatizado la importancia de los distintos contextos institucionales nacionales en las tasas de movilidad social y la distribución de oportunidades. ${ }^{12}$

En el ámbito específico de este trabajo, mi interés es analizar los efectos en el logro ocupacional de factores ligados al origen social y al mérito individual, con el fin de establecer hasta qué punto se ha avanzado o no en abatir la inequidad de oportunidades. Esta pregunta adquiere relevancia no sólo por los cambios en la estructura económica apuntados en la sección anterior, sino también en el marco de transformaciones más amplias, como son el de-

${ }^{12}$ Este debate teórico se ha trasladado a la esfera de los estudios empíricos sin resultados concluyentes. Por ejemplo, Biblarz, Bengtson y Bucur (1996) presentan datos a favor de la hipótesis de la reducción de los efectos de factores asociados al origen social en los Estados Unidos. En contraste, Erikson y Goldthorpe (1992) presentan abundantes evidencias en contra de esta hipótesis para varios países industrializados. Ganzeboom, Treiman y Ultee (1991) presentan una revisión detallada de este debate y de la investigación comparativa en la materia previa a la década de los noventa. 
bilitamiento de las políticas de bienestar del Estado mexicano, el deterioro de los niveles de vida de las familias asociado a las crisis económicas, la masificación de la educación básica acompañada de la segmentación de la educación superior en planteles públicos y privados, y la notable reducción de la inmigración rural a Monterrey.

\section{Datos y metodología}

Los datos para el análisis de la movilidad ocupacional provienen de dos fuentes: la "Encuesta sobre movilidad social y geográfica en Monterrey", realizada por Balán, Browning y Jelin en 1965 (Balán, Browning y Jelin, 1977), y la "Encuesta sobre movilidad ocupacional y curso de vida en Monterrey", realizada a finales de 2000 (Solís, 2002) y diseñada para lograr compatibilidad con la encuesta realizada por Balán, Browning y Jelin en 1965. Ambas encuestas recopilan las historias ocupacionales completas de los hombres adultos residentes en Monterrey, ${ }^{13}$ así como la ocupación de sus padres al nacimiento y otras variables relevantes, como la escolaridad, el origen migratorio, y otras características sociodemográficas.

A partir de esta información contrasto la movilidad ocupacional intergeneracional a los 33 años de edad de cuatro cohortes de nacimiento de hombres residentes en Monterrey: 1905-1920, 1921-1932, 1940-1954 y 1955-1967. Cada una de estas cohortes llegó a los 33 años de edad en distintos periodos del desarrollo económico de Monterrey. La primera cohorte lo hizo entre 1938 y 1953, al inicio del periodo de sustitución de importaciones; la cohorte 1921-1932 entre 1954 y 1965, durante los años de mayor expansión industrial de Monterrey; la cohorte 1940-1954 entre 1973 y 1987, al final de la sustitución de importaciones y durante la crisis económica de los ochenta; y la cohorte 1955-1967 entre 1988 y 2000, en el periodo de crecimiento basado en la expansión internacional de las empresas locales y la diversificación sectorial de la economía regiomontana. En este sentido, la movilidad ocupacional de las cohortes refleja los cambios en las condiciones económicas y sociales experimentados en la ciudad durante la segunda mitad del siglo pasado.

El Cuadro 3 muestra la clasificación ocupacional que utilizo en este estudio. En el mayor nivel de agregación, esta clasificación distingue cuatro cate-

${ }^{13}$ Desafortunadamente, en ninguna de las dos encuestas se recopiló información para las mujeres, por lo que en este trabajo sólo analizo la movilidad ocupacional masculina. Una tarea importante a futuro es recolectar información retrospectiva sobre las trayectorias laborales femeninas, lo que permitiría incorporar en el análisis a un segmento creciente de la fuerza de trabajo regiomontana. 
gorías ocupacionales (desde "No manual de alta calificación" hasta "Manual de baja calificación"), elaboradas a partir de la doble dicotomía que distingue, por un lado, entre ocupaciones manuales y no manuales y, por el otro, entre ocupaciones de baja y alta calificación. En el menor nivel de agregación, la clasificación identifica ocho grupos ocupacionales (desde "Profesionistas y gerentes" hasta "Trabajadores agrícolas"). En ambos niveles de agregación adopto el supuesto de que existe una jerarquía en términos de retribuciones económicas, prestigio y otros activos entre los miembros de las ocupaciones, de tal forma que la movilidad entre ellas puede ser caracterizada como de tipo vertical. ${ }^{14}$ La utilización de una u otra clasificación ha dependido en gran medida del número de casos disponibles en las muestras, aunque el nivel de agregación no altera significativamente los resultados sustantivos de este trabajo. ${ }^{15}$

El arsenal técnico de los estudios de estratificación y movilidad social ha alcanzado un alto grado de sofisticación. No obstante, en este artículo he optado por utilizar principalmente técnicas descriptivas para identificar las principales tendencias en la movilidad ocupacional. Solamente utilizo modelos de regresión logística para el análisis de los factores que inciden sobre el logro ocupacional individual, pues esta técnica permite poner a prueba hipótesis en torno a los efectos de los orígenes sociales una vez que se controla la movilidad estructural. Las características y ventajas de estos modelos se discuten en la sección respectiva.

\section{La continuidad de la movilidad estructural ascendente}

Como señalé antes, Monterrey experimentó amplias transformaciones en su mercado de trabajo durante las dos últimas décadas del siglo pasado, entre las que destacan la rápida terciarización y el incremento relativo de las ocupaciones no manuales. El contraste de la ocupación que tenían a los 33 años de edad los miembros de las cuatro cohortes de nacimiento (Cuadro 4) refleja estas transformaciones. Puede apreciarse, en primer lugar, que las ocupaciones manuales de baja calificación (últimos tres grupos) perdieron gradualmente importancia como fuente de empleo: en la cohorte 1905-1920, la pro-

${ }^{14}$ En el caso de Monterrey este supuesto no sólo tiene un sustento teórico, sino también empírico. Véase Solís (2002).

${ }^{15}$ Esta clasificación es bastante parecida al esquema propuesto por Erikson, Goldthorpe y Portocarero (1979), aunque se le hicieron algunas modificaciones para ajustarse a la información disponible y a ciertas especificidades de los mercados de trabajo urbanos en México (Solís, 2002). 


\section{Cuadro 3}

Clasificación de ocupaciones

Nivel de agregación

Cuatro grupos Ocho grupos Ocupaciones que integran el grupo

I. No manual I. Profesionistas Profesionistas; gerentes y directivos

de alta

y gerentes

calificación

de alto nivel en los sectores público

y privado; profesores universitarios.

II. No manual

II.A Empleados

Directivos de nivel medio en el sector

de baja especializados

público y privado; técnicos; maestros

calificación

de nivel inferior al universitario; artistas

y deportistas; dueños de comercios

establecidos.

II.B Empleados Trabajadores de rutina en oficinas

de oficina (archivistas, secretarios, etc.). Agentes

y agentes

de ventas en seguros o bienes raíces.

de ventas

II.C Empleados Empleados de ventas en negocios

de ventas establecidos; supervisores en la industria.

y trabajadores

de control

III. Manual

de alta

calificación

IV. Manual de baja calificación
III. Trabajadores

manuales

especializados

IV.A Trabajadores

de baja

calificación

en servicios

IV.B Trabajadores

manuales sin

especialización
Operadores de maquinaria; artesanos; choferes y otros conductores de vehículos; obreros especializados.

Vendedores ambulantes; trabajadores en servicios personales; trabajadores en servicios domésticos; trabajadores en servicios de seguridad.

Peones; ayudantes; aprendices de artesano; obreros no especializados; trabajadores en la construcción.

IV.C Trabajadores Trabajadores en actividades agrícolas. agrícolas 


\section{Cuadro 4}

Distribución porcentual de los hombres pertenecientes a cuatro cohortes de nacimiento según su ocupación a los 33 años de edad*

\begin{tabular}{lrrrr}
\hline & \multicolumn{3}{c}{ Cohorte de nacimiento } \\
\cline { 2 - 5 } & $1905-$ & $1921-$ & $1940-$ & $1955-$ \\
& 1920 & 1932 & 1954 & 1967 \\
\hline Ocupación a los 33 años de edad* & 5.1 & 7.8 & 14.1 & 14.1 \\
\hline Profesionistas y gerentes & 6.7 & 6.8 & 14.7 & 16.2 \\
Empleados especializados & 9.5 & 10.9 & 10.1 & 9.4 \\
Empleados de oficina y agentes de ventas & 3.8 & 2.7 & 7.0 & 11.1 \\
Empleados de ventas y trabajadores de control & 31.1 & 34.6 & 25.6 & 29.6 \\
Trabajadores manuales especializados & 12.6 & 12.0 & 7.7 & 7.6 \\
Trabajadores de baja calificación en servicios & 28.9 & 23.8 & 20.2 & 11.7 \\
Trabajadores manuales sin especialización & 2.3 & 1.4 & 0.6 & 0.3 \\
Trabajadores agrícolas & 100.0 & 100.0 & 100.0 & 100.0 \\
Total & 412 & 399 & 567 & 460 \\
Número de casos & & & & \\
\hline
\end{tabular}

* Sólo se incluyen quienes residían en Monterrey a los 33 años de edad.

Fuentes: Cohortes 1905-1932: Encuesta sobre trabajo y migración en Monterrey, 1965.

Cohortes 1940-1967: Encuesta sobre movilidad ocupacional y curso de vida en Monterrey, 2000.

porción de trabajadores en este tipo de ocupaciones alcanzaba $43.8 \%$; este porcentaje se redujo a $37.2 \%$ en la cohorte $1921-1932$, a $28.5 \%$ en la cohorte $1940-1954$, y a $19.6 \%$ en la cohorte 1955-1967. Por otra parte, el peso relativo de las ocupaciones manuales de alta calificación se incrementó entre la cohorte 1905-1920 y la cohorte 1921-1932, lo que refleja la expansión del empleo industrial durante la época dorada de la sustitución de importaciones; luego decae a $25.6 \%$ en la cohorte $1940-1954$, y se recupera a $29.6 \%$ en la cohorte más joven. Por último, la importancia de las ocupaciones no manuales, tanto de alta como baja calificación, se incrementa gradualmente en las tres primeras cohortes, y permanece constante entre la tercera y cuarta cohorte. Estos cambios son consistentes con las tendencias en la estructura ocupacional regiomontana presentadas en el Cuadro 2, y sugieren que, al menos en términos de la estructura ocupacional propuesta, existe en las cohortes sucesivas una tendencia de desconcentración del empleo en actividades manuales e incremento de las ocupaciones no manuales. Este "ajuste hacia arriba" en la estructura ocupacional se presenta con mayor intensidad 
en las tres primeras cohortes. De hecho, el único cambio que destaca en la última cohorte es la reducción de las ocupaciones manuales sin especialización (de 20.2 a 11.7\%), compensado por los incrementos en las ocupaciones manuales especializadas (de 25.6 a $29.6 \%$ ) y las ocupaciones de ventas y control (de 7.0 a 11.1 por ciento).

¿Cuál fue el logro ocupacional de los hombres regiomontanos con relación a sus padres? ¿Se refleja el cambio estructural hacia posiciones no manuales en una mayor movilidad intergeneracional? Con el fin de responder a estas preguntas, elaboré tablas de movilidad intergeneracional para cada cohorte con base en la ocupación del padre al nacimiento del entrevistado y la ocupación del entrevistado a los 33 años de edad (Cuadro 5). El contraste entre los marginales de padres e hijos nos permite estimar la magnitud de la movilidad estructural, esto es, el cambio absoluto en las distribuciones ocupacionales entre generaciones. ${ }^{16}$ Existe un marcado incremento en la movilidad estructural entre cohortes: en la cohorte 1905-1920 fue de 15\%, en la cohorte 1921-1932 fue 23\%, en la cohorte 1940-1954 fue 28\%, y en la cohorte 1955-1967 fue 31\%. Si se revisan con detenimiento los marginales de padres e hijos puede notarse que este incremento en la movilidad estructural se debe básicamente al cambio hacia ocupaciones no manuales en las distribuciones ocupacionales de los hijos.

El análisis de la distribución de casos al interior de las tablas permite caracterizar más detalladamente la movilidad ocupacional intergeneracional. En la diagonal se ubican los individuos que no experimentaron movilidad ocupacional intergeneracional, mientras que en el triángulo inferior izquierdo se encuentran quienes tuvieron movilidad ascendente y en el superior derecho quienes tuvieron movilidad descendente. El Cuadro 6 presenta medidas resumen de estos tipos de movilidad. Tanto la movilidad descendente como la inmovilidad tienden a disminuir gradualmente. El porcentaje de individuos que experimentaron movilidad descendente pasó de $19.4 \%$ en la cohorte $1905-1920$ a $8.3 \%$ en la cohorte $1955-1967$, mientras que quienes no experimentaron movilidad se redujeron de $49.1 \%$ en la cohorte $1921-1932$ a $39.5 \%$ en la cohorte $1955-1967$. En cambio, se presenta un claro incremento en el porcentaje de individuos que experimentaron movilidad intergeneracional ascendente, de $34.9 \%$ en la cohorte $1905-1920$ a $52.2 \%$ en la cohorte 1955-1967.

${ }^{16}$ La movilidad estructural se calcula a través del índice de disimilitud, esto es, la sumatoria del valor absoluto de las diferencias entre los totales (marginales) de hijos y padres, divididos entre dos. Por ejemplo, en la primera cohorte, la movilidad estructural se calcula de la siguiente manera: $(|5.1-4.4| / 2)+(|20.6-18.0| / 2)+(|29.3-17.2| / 2)+(|45.0-60.5| / 2)=15.5$. 

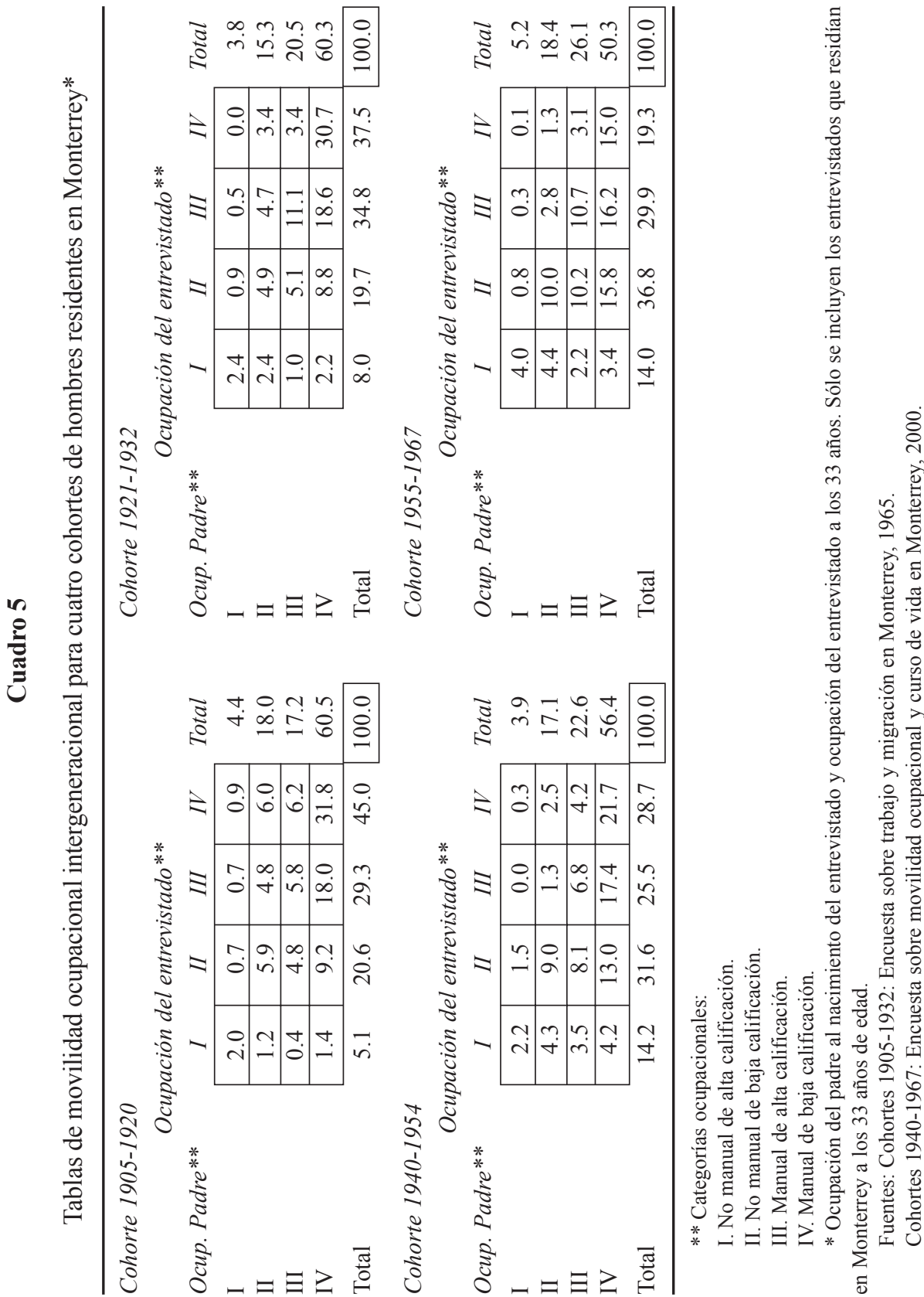

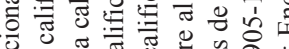

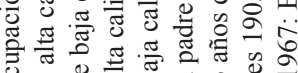
उٓ

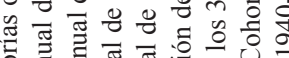

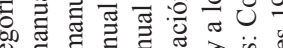
预

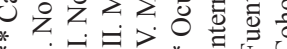
* 


\section{Cuadro 6}

Medidas resumen de movilidad ocupacional intergeneracional para cuatro cohortes de hombres residentes en Monterrey

\begin{tabular}{lrccr}
\hline & $1905-1920$ & $1921-1932$ & $1940-1954$ & $1955-1967$ \\
\hline Movilidad ascendente & 34.9 & 38.1 & 50.6 & 52.2 \\
No hubo movilidad & 45.7 & 49.1 & 39.7 & 39.5 \\
Movilidad descendente & 19.4 & 12.8 & 9.7 & 8.3 \\
Total & 100.0 & 100.0 & 100.0 & 100.0 \\
\hline
\end{tabular}

Fuente: Cuadro 5.

En resumen, las tablas de movilidad ocupacional muestran un claro incremento entre cohortes en la movilidad ocupacional ascendente. Este incremento se manifiesta tanto en la distribución de marginales, donde un creciente número de hijos se concentra en ocupaciones no manuales, como en la distribución de casos al interior de la tabla, donde el porcentaje que experimenta movilidad ascendente se incrementa hasta alcanzar más de $50 \%$ en la última cohorte. En este sentido, el análisis de cohortes revela que la movilidad ocupacional ascendente de corte estructural que predominó en Monterrey hasta antes de los ochenta no se interrumpió con la crisis y el cambio estructural de las dos últimas décadas. La diferencia es que en este último periodo la movilidad ascendente estuvo crecientemente vinculada a la expansión de las actividades no manuales, mientras que en el periodo precedente provino del crecimiento de las posiciones manuales de alta calificación.

\section{El debilitamiento de la correlación entre ocupaciones e ingresos}

Una pregunta que surge de inmediato al revisar estas tendencias es en qué medida la movilidad estructural ascendente se tradujo en una mejora en las condiciones de vida. Este es un tema complejo, pues, tal como señalé antes, junto con la transformación de la estructura ocupacional pudieron presentarse cambios en las retribuciones de cada ocupación en cada una de las dimensiones de la estratificación social (i.e., ingresos, prestigio, poder, capital social, acceso a bienes culturales, etc.). Más aún, es posible que en algunos casos las variaciones vayan en distinto sentido dependiendo de la dimensión que se someta a consideración. Debido a la carencia de información, es imposible hacer un recuento exhaustivo de las variaciones en el tiempo en cada una 
de estas dimensiones. No obstante, los datos disponibles sí nos permiten explorar a grandes rasgos los cambios en los ingresos que, debido a su alto grado de convertibilidad con otros bienes y activos, constituyen una de las dimensiones fundamentales de la estratificación social.

Como señalé antes, una de las tendencias de la economía mexicana durante las dos últimas décadas del siglo pasado fue la reducción de los ingresos laborales. No obstante, en Monterrey esta reducción no fue similar en todas las ocupaciones, como lo muestra el Cuadro 7, que presenta los cuartiles y la mediana del ingreso por ocupación para los hombres regiomontanos en 1965, 1987, y 2000. ${ }^{17}$ Se aprecia que en 1965 existía una clara correlación positiva entre ocupaciones e ingresos. La mediana del ingreso para los trabajadores manuales sin especialización alcanzaba los 3178 pesos, esto es, siete veces menos que el ingreso de los profesionistas y gerentes (23 844 pesos). Los trabajadores manuales especializados también tenían ingresos significativamente superiores a los no calificados (4 327 pesos, lo que representa $36 \%$ más que el ingreso de los trabajadores manuales sin especialización). Para los trabajadores manuales, el acceso a las posiciones no manuales de baja calificación representaba la posibilidad de ganancias significativas en los ingresos. Así, por ejemplo, el ingreso mediano de los empleados en ventas y trabajadores de control ( 7385 pesos) era $71 \%$ mayor al de los trabajadores manuales especializados, y más que el doble del de los trabajadores manuales de baja calificación. Estos datos revelan que en 1965 existía una clara progresión en el monto de los ingresos en la medida que se ascendía en la jerarquía ocupacional.

El panorama cambió notablemente para el año $2000 .{ }^{18}$ Sin excepción, en todos los grupos ocupacionales se presenta una reducción de los ingresos reales. No obstante, estas reducciones son significativamente mayores para los trabajadores no manuales. La mediana de los ingresos laborales para los profesionistas y gerentes cayó 58\%; la de los trabajadores no manuales especializados en $41 \%$; la de los trabajadores de oficinas y de ventas en $48 \%$, y la de los empleados en ventas y trabajadores de control en 53\%. En cambio, los ingresos de los trabajadores manuales cayeron en menor proporción (entre el $18 \%$ y el 30\%). En consecuencia, la brecha de ingresos entre los trabajadores manuales y no manuales se redujo, pero no como resultado de la mejora de los ingresos de los primeros, sino por el mayor empobrecimiento de los

${ }^{17}$ Los ingresos están actualizados a su valor real en pesos para el tercer trimestre de 2000.

${ }^{18}$ Los ingresos para 1987 reflejan el efecto coyuntural de la crisis en la que se encontraba sumergido el país en aquel año, por lo que, si bien ilustran el grado en que se contrajeron los ingresos durante la recesión, deben ser interpretados con cautela cuando se trata de analizar las tendencias de largo plazo. Por esta razón, realizo la comparación con el año 2000. 


\section{Cuadro 7}

Cuartiles y mediana de los ingresos laborales

mensuales de los hombres regiomontanos, por grupos de ocupaciones, 1965, 1987 y $2000^{*}$

\begin{tabular}{lrrr}
\hline Primer Cuartil & 1965 & 1987 & 2000 \\
\hline Profesionistas y gerentes & 14995 & 3984 & 6000 \\
Empleados especializados & 3695 & 2741 & 3010 \\
Empleados de oficina y agentes de ventas & 4113 & 2398 & 2580 \\
Empleados de ventas y trabajadores de control & 5053 & 2124 & 2580 \\
Trabajadores manuales especializados & 3446 & 2072 & 2580 \\
Trabajadores de baja calificación en servicios & 2393 & 1987 & 1800 \\
Trabajadores manuales sin especialización & 2792 & 1919 & 2150 \\
Total & 3078 & 2056 & 2580 \\
\hline Mediana & 1965 & 1987 & 2000 \\
\hline Profesionistas y gerentes & 23844 & 6374 & 10000 \\
Empleados especializados & 7291 & 3736 & 4300 \\
Empleados de oficina y agentes de ventas & 5770 & 3736 & 3010 \\
Empleados de ventas y trabajadores de control & 7385 & 2878 & 3440 \\
Trabajadores manuales especializados & 4327 & 2741 & 3010 \\
Trabajadores de baja calificación en servicios & 3257 & 2261 & 2580 \\
Trabajadores manuales sin especialización & 3178 & 2056 & 2580 \\
Total & 4113 & 2741 & 3440 \\
\hline Tercer Cuartil & 1965 & 1987 & 2000 \\
\hline Profesionistas y gerentes & 32086 & 8923 & 17200 \\
Empleados especializados & 12804 & 5737 & 8000 \\
Empleados de oficina y agentes de ventas & 9071 & 4908 & 4928 \\
Empleados de ventas y trabajadores de control & 11423 & 4780 & 5880 \\
Trabajadores manuales especializados & 6204 & 3426 & 4300 \\
Trabajadores de baja calificación en servicios & 4345 & 2741 & 3440 \\
Trabajadores manuales sin especialización & 3939 & 2422 & 3440 \\
Total & 6946 & 4111 & 5200 \\
\hline & & & \\
\hline
\end{tabular}

* Se incluyen solamente los hombres ocupados entre 20 y 60 años de edad. Los ingresos son ajustados a su valor real en pesos para el tercer trimestre de 2000, con base en las cifras oficiales de inflación nacionales publicadas por El Banco de México e INEGI. 2000 .

Fuentes: Encuesta sobre movilidad social y geográfica en Monterrey, 1965; ENEU, 1987 y 
últimos. Así, por ejemplo, si en 1965 el ingreso mediano de un empleado en ventas o trabajador de control era $71 \%$ superior al de un trabajador manual calificado, en el año 2000 era sólo de 14 por ciento.

Si además de esto se considera el rango de variabilidad de los ingresos en cada grupo ocupacional (primer y tercer cuartil), entonces se podrá apreciar que, en relación con lo que ocurría durante el auge de la sustitución de importaciones, hoy en día es más probable encontrar trabajadores no manuales que tengan ingresos similares o incluso inferiores a los de los trabajadores manuales. En síntesis, estas tendencias indican un debilitamiento de la correlación positiva entre ocupaciones e ingresos $y$, por consiguiente, una reducción de las ventajas económicas asociadas a la movilidad ocupacional ascendente.

\section{Persistencia de la inequidad de oportunidades}

Junto con la reducción de los ingresos en las ocupaciones no manuales, la estratificación ocupacional en Monterrey presenta otra señal de retroceso: la persistencia e, incluso, el probable incremento en tiempos recientes de la inequidad social en el acceso a las oportunidades laborales. Como señalé arriba, existe un fuerte debate en torno a los cambios en la equidad de oportunidades asociados a la industrialización y los procesos de modernización. Es importante retomar este debate en las sociedades latinoamericanas, a la luz de las transformaciones económicas y sociales que han experimentado en las últimas décadas. Los estudios sobre la pobreza y la desigualdad de ingresos han documentado los efectos de las crisis económicas, las políticas de ajuste y la liberalización económica sobre los niveles de bienestar y la desigualdad de ingresos, pero se sabe poco en torno a la forma en que estas transformaciones han incidido sobre la desigualdad de oportunidades laborales. ¿Sugieren que el acceso a las oportunidades laborales es más equitativo o más desigual en relación con los orígenes sociales de los individuos?

Para intentar responder estas preguntas en el caso de Monterrey es necesario utilizar modelos de regresión de tipo loglineal o logístico, los cuales permiten estimar el efecto de los orígenes sociales sobre el logro ocupacional individual, al tiempo que controlan el efecto de la movilidad estructural, así como de otras variables. ${ }^{19}$ En este caso, utilizo modelos de regresión

${ }^{19}$ Por limitaciones de espacio, no es posible profundizar aquí en torno a la pertinencia metodológica de utilizar modelos basados en razones de momios para controlar el efecto de la movilidad estructural (se pueden encontrar más detalles en Solís (2002)). Basta señalar que el 
logística ordenados. Estos modelos permiten comparar el riesgo de que un individuo con el estrato social de origen $x$ logre una ocupación de mayor jerarquía que otro perteneciente al estrato social de referencia $y$, independientemente de otras variables incluidas en el modelo (Powers y Xie, 2000). Este riesgo diferencial es expresado por medio de "razones de momios" (odds ratios). Si el valor estimado de la razón de momios no varía significativamente de 1 , entonces no hay diferencias en el logro entre quienes tienen un estrato de origen $x$ y $y$. Si la razón de momios es significativamente mayor a 1, entonces la probabilidad de logro mayor es para el estrato $x$. Por el contrario, si la razón de momios es significativamente menor a 1, entonces la probabilidad de logro es mayor para el estrato $y$. Con el fin de explorar los cambios en el tiempo en los efectos del estrato social de origen sobre el logro ocupacional, ajusto cuatro modelos similares para cada una de las cohortes.

Los resultados de los modelos aparecen en el Cuadro 8. Se presentan dos modelos diferentes para cada cohorte. En el primer modelo (panel superior), se introduce, además de la ocupación del padre al nacimiento, que es nuestro indicador del estrato de origen, la variable "Comunidad de origen", que denota el origen migratorio del individuo (nativo frente a inmigrante), ${ }^{20}$ y que también puede ser interpretada como una variable asociada a los orígenes sociales. En este sentido, en este primer modelo los efectos del estrato social de origen se pueden interpretar como si fueran independientes del origen migratorio. En el segundo modelo (panel inferior), se incluye, además de las dos variables anteriores, el nivel de escolaridad. Es ampliamente reconocido que parte del efecto de los orígenes sociales (tanto de clase como migratorios) sobre el logro ocupacional está mediado por el logro educativo (Blau y Duncan, 1967), por lo que al introducir esta última variable al modelo estamos en condiciones de estimar la influencia directa del estrato de origen sobre el logro ocupacional, al margen de su efecto indirecto a través de la escolaridad.

incremento en la movilidad estructural (esto es, el aumento en las probabilidades absolutas de movilidad ocupacional ascendente) puede llevar a conclusiones erróneas en torno a las probabilidades relativas de movilidad, esto es, las probabilidades de movilidad social de determinado grupo social en relación con las de otro grupo. Las razones de momios que resultan de los modelos de regresión de tipo logístico o loglineal no se ven afectadas por la movilidad estructural y, por lo tanto, reflejan sólo las probabilidades relativas de movilidad.

${ }^{20}$ La comunidad de origen se obtiene al codificar el tamaño de la comunidad donde el individuo residió por más tiempo entre los 5 y 15 años de edad. Si bien la variable no distingue entre inmigrantes rurales y urbanos, la mayoría de los hombres inmigrantes a Monterrey han provenido de zonas rurales, por lo que la categoría de inmigrantes puede ser equiparada a la de inmigrantes rurales. 


\section{Cuadro 8}

Efectos de los orígenes sociales y el nivel de escolaridad sobre el logro ocupacional de los hombres regiomontanos. Modelos logísticos ordenados específicos por cohorte ${ }^{1}$

\begin{tabular}{lcccc}
\hline Cohorte de nacimiento & $1905-1920$ & $1921-1932$ & $1940-1954$ & $1955-1967$ \\
\hline Modelo 1 & & & & \\
\hline $\begin{array}{l}\text { Ocupación del padre al nacimiento } \\
\quad \text { No manual de alta calificación }\end{array}$ & $6.417^{* *}$ & $11.126^{* *}$ & $3.350^{* *}$ & $9.442^{* *}$ \\
$\quad$ No manual de baja calificación (ref.) & - & - & - & - \\
$\quad \begin{array}{l}\text { Manual de alta calificación } \\
\text { Manual de baja calificación }\end{array}$ & 0.764 & 0.636 & $0.423^{* *}$ & $0.314^{* *}$ \\
$\begin{array}{l}\text { Comunidad de origen } \\
\quad \text { Otra (ref.) }\end{array}$ & $0.423^{* *}$ & $0.249^{* *}$ & $0.208^{* *}$ & $0.181^{* *}$ \\
$\quad$ Monterrey & - & & & - \\
-2LL & $1.547^{* *}$ & $1.609^{* *}$ & $1.911^{* *}$ & 1.111 \\
\hline
\end{tabular}

Modelo 2

\begin{tabular}{|c|c|c|c|c|}
\hline \multicolumn{5}{|l|}{ Ocupación del padre al nacimiento } \\
\hline No manual de alta calificación & 1.356 & $7.431 * *$ & 0.869 & $4.170 * *$ \\
\hline No manual de baja calificación (ref.) & - & - & - & - \\
\hline Manual de alta calificación & 1.230 & 1.135 & $0.564 * *$ & $0.599 *$ \\
\hline Manual de baja calificación & 0.814 & 0.624 & $0.563 * *$ & $0.347 *$ \\
\hline \multicolumn{5}{|l|}{ Nivel de escolaridad del entrevistado } \\
\hline Estudios Superiores & $22.765^{* *}$ & $35.266^{* *}$ & $49.683 * *$ & $16.750 * *$ \\
\hline Secundaria/Preparatoria (ref.) & - & - & - & - \\
\hline Primaria Completa & $0.162 * *$ & $0.411 * *$ & $0.449 * *$ & $0.466 * *$ \\
\hline Menos de Primaria Completa & $0.073 * *$ & $0.156^{* *}$ & $0.151 * *$ & $0.227 * *$ \\
\hline \multicolumn{5}{|l|}{ Comunidad de origen } \\
\hline Otra (ref.) & - & - & - & - \\
\hline Monterrey & 1.233 & 1.297 & 1.254 & 0.833 \\
\hline$-2 L L$ & 163.33 & 243.14 & 400.73 & 249.65 \\
\hline $\mathrm{n}$ & 384 & 367 & 565 & 456 \\
\hline
\end{tabular}

${ }^{1}$ La variable dependiente es la posición en la jerarquía ocupacional a los 33 años de edad, con base en la clasificación de cuatro grupos descrita en el Cuadro 1.

$* \mathrm{p}<0.1 * * \mathrm{p}<0.05$.

Fuentes: 1905-1932: Encuesta sobre movilidad social y geográfica en Monterrey, 1965. 1940-1967: Encuesta sobre movilidad ocupacional y curso de vida en Monterrey, 2000. 
Los resultados del panel superior indican que el estrato de origen tiene un efecto significativo sobre el logro ocupacional en las cuatro cohortes. En la cohorte 1905-1920, los momios de lograr una mejor ocupación son 6.417 veces mayores para los hijos de trabajadores no manuales con alta calificación en relación con los hijos de trabajadores no manuales de baja calificación. ${ }^{21}$ Esta distancia se incrementa a 11.126 veces en la cohorte 1921-1932, luego disminuye a 3.350 veces en la cohorte $1940-1954$ y, finalmente, se incrementa a 9.442 veces en la cohorte 1955-1967. En contraste, las oportunidades de lograr mejores ocupaciones son menores para los hijos de trabajadores manuales de alta calificación, aunque estas diferencias sólo son significativas en las últimas dos cohortes. Así, en la cohorte más joven (1955-1967), los momios de lograr una ocupación de mayor jerarquía son tres veces menores (0.314) para los hijos de trabajadores manuales de alta calificación que para los descendientes de trabajadores no manuales de baja calificación. De igual manera, la probabilidad de lograr una mejor ocupación es significativamente menor para los hijos de trabajadores manuales de baja calificación y, además, la brecha con respecto a los trabajadores no manuales de baja calificación se incrementa con el tiempo (los momios pasan de 0.423 en la cohorte 1905-1920 a 0.181 en la cohorte 1955-1967).

Estos resultados por sí mismos son indicativos de que el estrato social de origen ejerce en todas las cohortes una importante influencia sobre el logro ocupacional, así como de que esta asociación no se debe al origen migratorio. Pero, ¿en qué medida la asociación entre el estrato de origen y el logro ocupacional se encuentra mediada por el logro educativo? Los resultados del segundo modelo, que incluyen el nivel de escolaridad, nos permiten explorar este problema. Puede notarse, en primer lugar, que la escolaridad y, particularmente, el obtener estudios universitarios, ejerce en todas las cohortes una fuerte influencia sobre el logro ocupacional. También se aprecia que en términos generales el efecto de la ocupación del padre disminuye en relación con el primer modelo, lo cual es esperable porque parte de su influencia es ahora absorbida por el nivel de escolaridad. No obstante, se puede observar que en las últimas dos cohortes el estrato de origen es todavía un importante determinante del logro ocupacional. De hecho, las diferencias en el logro ocupacional entre quienes provienen de ocupaciones manuales (tanto de alta como de baja calificación) y ocupaciones no manuales sin calificación, pasaron de ser no significativas en las primeras dos cohortes a ser significativas en las últimas dos, lo que sugiere que, una vez controlados los efectos del

\footnotetext{
${ }^{21}$ En todos los casos, los trabajadores no manuales de baja calificación son la categoría de referencia.
} 
nivel de escolaridad, la desigualdad por estrato de origen en las oportunidades laborales se ha incrementado, en lugar de decrecer. ${ }^{22}$ En síntesis, los resultados de ambos modelos sugieren que el efecto de los orígenes sociales sobre el logro ocupacional no decreció en las últimas dos cohortes e, incluso, parece haberse incrementado.

\section{Discusión y conclusiones}

Una de las grandes preocupaciones en las ciencias sociales de América Latina ha sido estudiar los efectos de las transformaciones económicas y sociales recientes sobre el bienestar de la población. Debido a que esta preocupación se ha orientado en su mayor parte a documentar los niveles de desigualdad del ingreso y de pobreza, existen pocas referencias que nos permiten explorar los efectos de largo plazo sobre la estratificación y la movilidad social. En este artículo, he propuesto retomar esta temática, a partir de un estudio de caso sobre la estratificación y la movilidad ocupacional en la ciudad de Monterrey.

De los resultados del estudio, puede concluirse que el régimen de estratificación y movilidad ocupacional que emerge en Monterrey luego de la crisis y la reestructuración económica de las dos últimas décadas presenta rasgos bastante contradictorios. En primer lugar, los cambios estructurales que experimentó la ciudad a partir de finales de los setenta se han traducido en una recomposición del mercado de trabajo que facilitó la movilidad estructural ascendente. El gradual incremento en las posiciones no manuales, tanto calificadas como no calificadas, facilitó el flujo intergeneracional de individuos de posiciones manuales a no manuales. En este sentido, la reestructuración del mercado de trabajo hizo posible que muchos jóvenes regiomontanos provenientes de familias obreras pudieran cristalizar sus aspiraciones de al-

${ }^{22}$ Una alternativa para corroborar empíricamente esta hipótesis es ajustar un modelo único de regresión para todas las cohortes, donde se incorpora la interacción entre la cohorte y la ocupación del padre, al tiempo que se controla el efecto del nivel de escolaridad y el origen migratorio. Los coeficientes de este modelo alternativo (no mostrados) confirman en términos generales los resultados ya descritos: los coeficientes negativos asociados a ocupaciones no manuales (tanto calificadas como no calificadas) se incrementan significativamente a partir de la tercera y cuarta cohorte, lo cual indica una mayor brecha en el logro entre hijos de trabajadores manuales e hijos de trabajadores no manuales de baja calificación. En cambio, no existen diferencias significativas por cohorte en el coeficiente asociado a trabajadores no manuales de alta calificación, lo que sugiere una mayor similitud en las probabilidades de logro entre trabajadores no manuales de alta y baja calificación. 
canzar trabajos no manuales como oficinistas, técnicos o, incluso, profesionistas.

No obstante, junto con el incremento en la movilidad estructural se presentan dos tendencias mucho menos alentadoras. La primera es que, en el marco de una generalizada caída en los ingresos laborales, la disminución relativa de los ingresos de los trabajadores no manuales ha sido mayor, por lo que su ventaja de ingresos en relación con las posiciones manuales se redujo. Esto significa que, vista desde una perspectiva de largo plazo, la movilidad ascendente hacia ocupaciones no manuales es hoy menos redituable económicamente que en el pasado. Si esto lo ligamos con el hecho de que gran parte de la movilidad estructural ascendente en Monterrey se ha dado hacia este tipo de ocupaciones, entonces el panorama resultante es el de una estructura ocupacional que gana en las posiciones de mayor jerarquía a costa de una reducción significativa de las remuneraciones a las mismas. Para continuar con el ejemplo del párrafo anterior, se podría afirmar que si bien muchos hijos de obreros lograron posiciones no manuales como oficinistas, técnicos o empleados en ventas, también es cierto que en muchas ocasiones sus ingresos eran similares o menores a los que sus padres tenían como obreros veinte años atrás e, incluso, no eran mayores a los de sus contemporáneos que siguen en posiciones manuales.

La segunda tendencia negativa es la continuidad e, incluso, el probable incremento, de la inequidad en el acceso a las oportunidades laborales. Si bien se ampliaron las oportunidades de ingreso a ocupaciones no manuales, el acceso a éstas continuó siendo determinado en buena medida por los orígenes sociales. Incluso, los resultados de los modelos por cohorte sugieren un incremento en la inequidad de oportunidades por estrato social de origen en el último trecho del siglo. Esto lleva a reflexionar en torno a la importancia de incorporar más activamente en la agenda de investigación sobre estratificación social en México y América Latina el análisis de la inequidad de oportunidades, particularmente en el contexto actual, en el que se debate y redefine el papel de las instituciones de bienestar social, las cuales cumplieron, aunque de manera deficiente, la función de "nivelar el terreno" y atenuar las disparidades sociales más extremas en el pasado.

Es precisamente la integración de estos rasgos contradictorios (movilidad estructural ascendente, reducción de las ganancias económicas asociadas a la movilidad ascendente, y permanencia de la inequidad de oportunidades) lo que delinea el perfil emergente de la estratificación ocupacional en Monterrey. No es difícil imaginar entonces que a los propios residentes de la ciudad el panorama del empleo se les presente como pleno de incertidumbres. Esto se refleja en diversos fenómenos, como son cierta desvalorización de las 
ocupaciones no manuales de baja calificación (como oficinistas o empleados en ventas); la percepción generalizada de que el mercado de trabajo no tiene más cabida para los egresados universitarios y la idealización del "negocio propio" como estrategia para evadir las barreras que el mercado de trabajo impone a la movilidad ascendente de ingresos. Al mismo tiempo, la inconformidad que pudo haberse generado tras las dificultades para lograr una movilidad sustantiva en lo económico también se vio atenuada porque esta situación se dio en un escenario de alta movilidad ocupacional ascendente de tipo estructural, que si bien no necesariamente se tradujo en mejoras sustanciales en el ingreso, sí pudo reflejarse en un cambio de "status" ocupacional. ${ }^{23}$

Como con todo estudio de caso, es importante tener cautela con la generalización de estos resultados a otros lugares, tanto de México como de otros países de América Latina. Si algo distingue a Monterrey de las otras metrópolis mexicanas, y de la mayoría de las grandes ciudades de América Latina, es su capacidad de adaptarse con relativo éxito a las condiciones económicas externas, lo que le ha permitido emerger con cierta prosperidad de la dificultosa reestructuración económica reciente. En este sentido, puede suponerse que el entorno estructural ha sido más favorable para la estratificación y la movilidad social en Monterrey que en las otras grandes ciudades mexicanas e, incluso, que en la mayoría de las grandes urbes latinoamericanas. De hecho, la comparación detallada del caso de Monterrey con el México urbano (Zenteno y Solís, 2003) muestra que si bien persiste cierta movilidad estructural en el entorno nacional, ésta es considerablemente menor a la observada en Monterrey, al tiempo que se observan menores tasas de movilidad ascendente y la persistencia en los efectos de los orígenes sociales sobre el logro ocupacional. Por otra parte, el trabajo reciente de la CEPAL para un conjunto de países de América Latina indicaría también una desaceleración de la movilidad estructural en la última década (CEPAL, 2000). No obstante, sería necesario profundizar con estudios comparativos más detallados para conocer a ciencia cierta si es que todas o algunas de las tendencias aquí descritas se reproducen en los distintos entornos regionales.

Por último, también es necesario acotar temporalmente estos hallazgos. Las tendencias señaladas reflejan, en todo caso, el saldo negativo de las primeras dos décadas de crisis y cambio estructural; dos décadas que en México estuvieron marcadas por tres crisis económicas, profundos ajustes estructurales, y sólo moderadas tasas de crecimiento económico. Lo que parece cla-

${ }^{23}$ Cabe señalar que otra importante válvula de escape para la tensión social ha sido la creciente incorporación de las mujeres unidas a la fuerza de trabajo, que al proporcionar ingresos adicionales a las familias de los sectores medios y bajos, aliviaron en parte los apremios domésticos originados por la caída de los ingresos de los varones. 
ro es que si se pretende lograr un cambio de rumbo en esta materia, esto dependerá no sólo de la generación de un crecimiento económico sostenido en los próximos años, sino también de la capacidad que se tenga para generar acuerdos institucionales que permitan un incremento sustancial en los ingresos y fomenten la equidad en el acceso a las oportunidades laborales.

Recibido: febrero, 2004

Revisado: agosto, 2004

Correspondencia: El Colegio de México, A. C./Centro de Estudios Sociológicos/Camino al Ajusco núm. 20/Col. Pedregal de Sta. Teresa, C. P. 01000/ Fax: 564504 64/correo electrónico: psolis@colmex.mx

\section{Bibliografía}

Alba, Carlos (1998), "Tres regiones de México ante la globalización: los casos de Chihuahua, Nuevo León y Jalisco", en Carlos Alba, Ilán Bizberg y Helène Rivière d'Arc (comps.), Las regiones ante la globalización, competitividad territorial y recomposición geográfica, México, El Colegio de México, Centro de Estudios Internacionales, pp. 189-261.

Balán, Jorge (1968), The Process of Stratification in a Developing Society: the Case of Monterrey, Mexico, Austin, Texas, Universidad de Texas en Austin, tesis de doctorado.

Balán, Jorge, Harley L. Browning y Elizabeth Jelin (1977), El hombre en una sociedad en desarrollo. Movilidad geográfica y social en Monterrey, México, Fondo de Cultura Económica.

Biblarz, Timothy J., Vern L. Bengtson y Alexander Bucur (1996), "Social Mobility across Three Generations", Journal of Marriage and the Family, vol. 58, núm. 1, pp. 188-200.

Blau, Peter M. y Otis D. Duncan (1967), The American Occupational Structure, Nueva York, John Wiley.

Boltvinik, Julio (2001), "Dinámica y características de la pobreza en México", en José Gómez de León y Cecilia Rabell (coords.), La Población de México: tendencias y perspectivas sociodemográficas hacia el Siglo XX, México, Fondo de Cultura Económica.

CEPAL (Comisión Económica para América Latina y el Caribe) (2000), Panorama social de América Latina 1999-2000, Santiago, onU.

Cerutti, Mario (2000), Propietarios, empresarios y empresa en el norte de México. Monterrey: de 1848 a la globalización, México, Siglo XXI.

Cortés, Fernando (1998), "Eficiencia y desigualdad. Un contrapunto", Espiral: estudios sobre Estado y Sociedad, vol. 4, núm. 12, pp. 169-200. 
DiPrete, Thomas A., Dominique Goux, Eric Maurin y Michael Tåhlin (2001), "Institutional Determinants of Employment Chances. The Structure of Unemployment in France and Sweden", European Sociological Review, vol. 17, núm. 3, pp. 233-254.

DiPrete, Thomas A., Paul M. De Graff, Ruud Luijkx y Michael Tåhlin (1997), "Collectivist versus Individualist Mobility Regimes? Structural Change and Job Mobility in Four Countries", American Journal of Sociology, vol. 103, núm. 2, pp. 318-358.

Dussel Peters, Enrique (2003), "Características de las actividades generadoras de empleo en la economía mexicana (1988-2000)”, Investigación Económica, vol. LXIII, núm. 243, pp. 123-154.

- (1997), La economía de la polarización. Teoría y evolución del cambio estructural de las manufacturas mexicanas (1988-1996), México, unAm-Editorial Jus.

Erikson, Robert y John H. Goldthorpe (1992), The Constant Flux: A Study of Class Mobility in Industrial Societies, Oxford, Clarendon Press.

Erikson, Robert, John H. Goldthorpe y Lucienne Portocarero (1979), "Intergenerational Class Mobility in Three Western European Societies: England, France and Sweden”, British Journal of Sociology, vol. 30, núm. 4, pp. 415-441.

Esping-Andersen, Gøsta (1993), Changing Classes Stratification and Mobility in Post-industrial Societies, Londres, Sage.

Filgueira, Carlos (2000), La actualidad de viejas temáticas: sobre los estudios de clase, estratificación y movilidad social en América Latina, Santiago, ONU-CEPAL.

Ganzeboom, Harry B. J., Donald J. Treiman y Wout C. Ultee (1991), "Comparative Intergenerational Stratification Research: Three Generations and Beyond", Annual Review of Sociology, vol. 17, pp. 277-302.

Germani, Gino (1963), "La movilidad social en la Argentina", en Seymour Martin Lipset y Reinhard Bendix (eds.), Movilidad Social en la Sociedad Industrial, Buenos Aires, Eudeba.

Giddens, Anthony (1989), La estructura de clases en las sociedades avanzadas, Madrid, Alianza Editorial.

González de la Rocha, Mercedes (1994), The Resources of Poverty: Women and Survival in a Mexican City, Oxford, Blackwell.

Grusky, David B. (1994), "The Contours of Social Stratification", en David B. Grusky (comp.), Social Stratification: Class, Race, and Gender in Sociological Perspective, Boulder, Colorado, Westview Press, pp. 3-35.

Grusky, David B. y Thomas A. DiPrete (1990), "Recent Trends in the Process of Stratification", Demography, vol. 27, pp. 617-637.

Hauser, Robert Mason y David L. Featherman (1977), The Process of Stratification: Trends and Analyses, Nueva York, Academic Press.

Hauser, Robert Mason, Shu-Ling Tsai y William Hamilton Sewell (1983), "A Model of Stratification with Response Error in Social and Psychological Variables", Sociology of Education, vol. 56, pp. 20-46.

Hout, Michael (2003), How Might Inequality Affect Intergenerational Mobility? A Review and an Agenda, Berkeley, California, University of California, Survey Research Center Working Paper. 
Kerbo, Harold R. (1996) Social Stratification and Inequality: Class Conflict in Historical and Comparative Perspective, Nueva York, McGraw-Hill.

Kingston, Paul W. (2000), The Classless Society, Stanford, California, Stanford University Press.

Lustig, Nora (1998), Mexico: The Remaking of an Economy, 2a ed., Washington, DC, Brookings Institution Press.

Mayer, Karl Ulrich (1991), "Life Courses in the Welfare State", en Walter R. Heinz (ed.), Theoretical Advances in Life Course Research, Weinheim, Deutscher Studien Verlag.

(1997), "Notes on a Comparative Political Economy of Life Courses", en F. Engelstad (ed.), Comparative Social Research, vol. 16, Methodological Issues in Comparative Social Science, Londres, JAI, pp. 203-226.

Muñoz, Humberto, Orlandina de Oliveira y Claudio Stern (1977), Migración y desigualdad social en la ciudad de México, México, unam, Instituto de Investigaciones Sociales.

Powers, Daniel A. y Yu Xie (2000), Statistical Methods for Categorical Data Analysis, San Diego, California, Academic Press.

Pozas, María de los Ángeles (2002), Estrategia internacional de la gran empresa mexicana en la década de los noventa, México, El Colegio de México, Centro de Estudios Sociológicos.

- (1993), Industrial Restructuring in Mexico: Corporate Adaptation, Technological Innovation, and Changing Patterns of Industrial Relations in Monterrey, La Jolla, California, Center for U.S.-Mexican Studies-El Colegio de la Frontera Norte.

Pozos Ponce, Fernando (1996), Metrópolis en reestructuración. Guadalajara y Monterrey, 1980-1989, Guadalajara, Universidad de Guadalajara.

Selby, Henry A., Arthur D. Murphy y Stephen A. Lorenzen (1990), The Mexican Urban Household: Organizing for Self-defense, Austin, University of Texas Press.

Sewell, William H., Archibald O. Haller y Alejandro Portes (1969), "The Educational and Early Occupational Attainment Process", American Sociological Review, vol. 34, pp. 82-92.

Solís, Patricio (2002), Structural Change and Men's Work Lives: Transformations in Social Stratification and Occupational Mobility in Monterrey, Mexico, Austin, Texas, Universidad de Texas en Austin, tesis de doctorado.

Treiman, Donald J. (1970), "Industrialization and Social Stratification", en Edward O. Laumann (ed.), Social Stratification: Research and Theory for the 1970s, Indianapolis, Bobbs-Merrill.

Tuirán, Rodolfo (1993), "Las respuestas de los hogares de sectores populares urbanos frente a la crisis: el caso de la ciudad de México", en Raúl Béjar Navarro, Héctor Hernández Bringas y Anne Bar-Din (eds.), Población y desigualdad social en México, Cuernavaca, Morelos, unAM-CRIM.

Zenteno, René y Patricio Solís (2003), “Tendencias recientes en la movilidad ocupacional en el México urbano", Guadalajara, VII Reunión Nacional de Investigación Demográfica en México. 